\title{
Genetics of Hypertensive Syndrome
}

\author{
Alejandro Martinez-Aguayo ${ }^{a} \quad$ Carlos Fardella ${ }^{b}$ \\ ${ }^{a}$ Endocrinology Unit, Department of Pediatrics, and ${ }^{b}$ Department of Endocrinology, Faculty of Medicine, \\ Pontificia Universidad Católica de Chile, Santiago, Chile
}

\section{Key Words}

Hypertension - Aldosterone - Familial hyperaldosteronism • Liddle's syndrome $\cdot$ Glucorticoid resistance $\cdot$ Congenital adrenal hyperplasia

\begin{abstract}
The knowledge of the genetic bases of hypertension has improved over the last decade; this area of research has high priority due to the high incidence of hypertension and its impact on public health. Monogenetic mineralocorticoid hypertension syndromes are associated with suppressed plasma renin activity due to excessive activation of the mineralocorticoid pathway. We review the pathophysiology, phenotype, and method of diagnosis for familial hyperaldosteronism type I and type II, hypertensive forms of congenital adrenal hyperplasia, 11 $\beta$-hydroxysteroid dehydrogenase type 2 deficiency, Liddle's syndrome, an activating mutation of the MR, and glucocorticoid resistance. We also review some genes that could contribute to essential hypertension.

Copyright $\odot 2009$ S. Karger AG, Basel
\end{abstract}

\section{Introduction}

Hypertension is the most prevalent, treatable risk factor for diseases of the heart, brain and kidneys. Available evidence suggests a major genetic impact on blood pres- sure regulation. Existing evidence suggests that the genetic contribution to blood pressure variation is about $30-50 \%$ [1]. However, hypertension is a multifactorial disorder that probably results from the inheritance of a number of susceptibility genes and that involves multiple environmental determinants. The possible candidate genes are components of the renin-angiotensin-aldosterone system, adducin, $\beta$-adrenoceptors, $G$ protein subunits, regulators of $G$ protein signaling (RGS) proteins, rho kinases, and $G$ protein receptor kinases (OMIM; $\# 145500$ ).

Inherited hypertension disorders may be mild, and electrolyte and acid-base abnormalities are often not present. Monogenic hypertension should therefore be included in the differential diagnosis of any child or adolescent with hypertension [2]. In this review, we present the genes involved in blood pressure regulation, and we discuss some associated syndromes.

\section{Monogenetic Mineralcorticoid Hypertension Syndromes}

The term of 'monogenetic mineralocorticoid hypertension' [3] refers to hypertension that results from a single genetic mutation causing excessive sodium resorption via the epithelial sodium channel $(\mathrm{ENaC})$ in the distal tubule and collecting duct. This condition is characterized by suppressed plasma renin activity (PRA) as result

\section{KARGER \\ Fax +4161306 1234 \\ E-Mail karger@karger.ch}

www.karger.com
(C) 2009 S. Karger AG, Basel

0301-0163/09/0715-0253\$26.00/0

Accessible online at:

www.karger.com/hre
Carlos E. Fardella

Department of Endocrinology, Faculty of Medicine

Pontificia Universidad Católica de Chile

Lira 85, piso 5, Santiago (Chile)

Tel. +56 02354 3095, Fax + 5602638 5675, E-Mail cfardella@med.puc.cl 


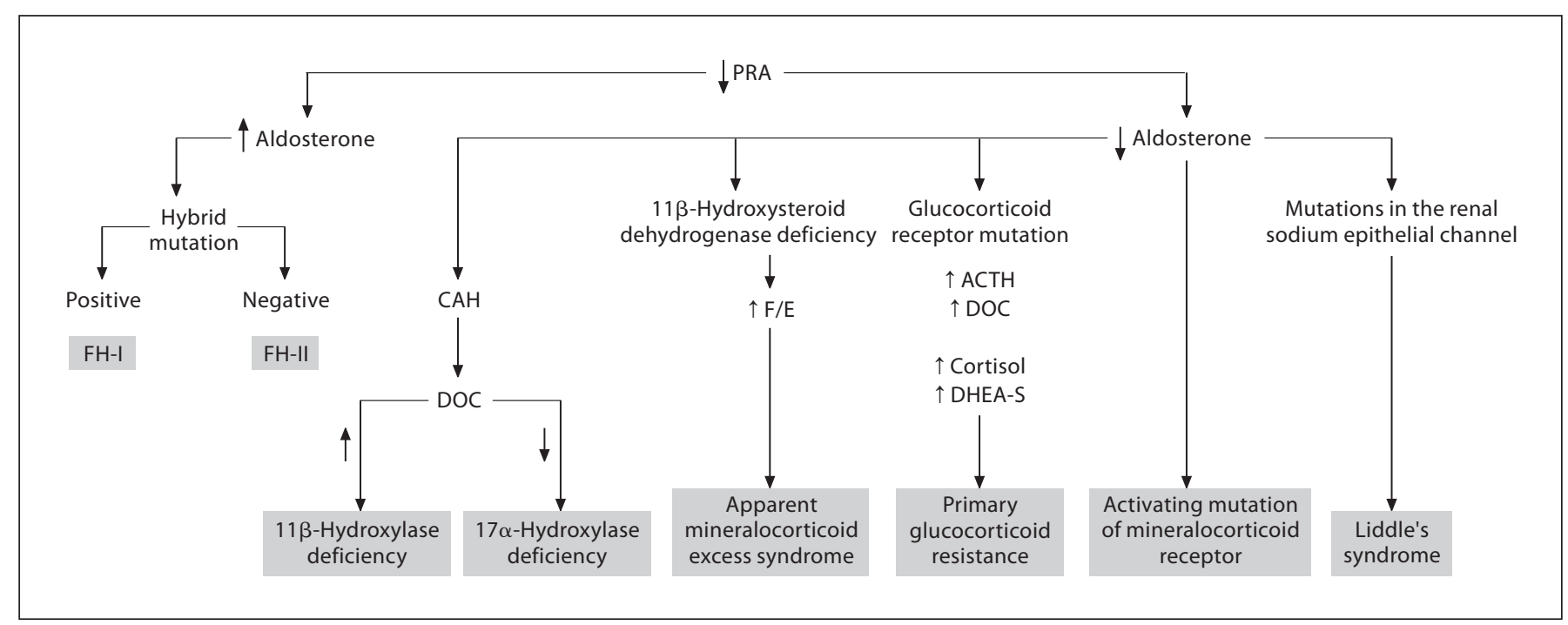

Fig. 1. Monogenetic mineralocorticoid hypertension syndromes. PRA = Plasma renin activity; $\mathrm{FH}=$ family hyperaldosteronism; $\mathrm{CAH}=$ congenital adrenal hyperplasia; $\mathrm{DOC}=$ deoxycortisol; $\mathrm{F} / \mathrm{E}=$ cortisol/cortisone ratio.

of sodium retention, and it is associated with potassium and hydrogen ion wasting, which can lead to hypokalemia and alkalosis.

This type of hypertension can be accompanied by either excessive aldosterone production (associated with suppressed PRA) or suppressed aldosterone production (plasma aldosterone low or undetectable) (fig. 1, 2; table 1).

\section{Conditions Associated with Excessive Aldosterone Production}

\section{Familial Hyperaldosteronism Type I}

(OMIM; \#103900)

Glucocorticoid-remediable aldosteronism (GRA) is an autosomal dominant disorder characterized by hypertension, variable hyperaldosteronism, low PRA, normal or decreased serum potassium and abnormal adrenal steroid production, including 18-oxocortisol and 18-hydroxycortisol. It is caused by fusion of the cytochrome P450, subfamily XIB, polypeptide 1 gene (CYP11B1, 610613) and the cytochrome P450, subfamily XIB, polypeptide 2 gene (CYP11B2, 124080). The chimeric gene, in which the 5-prime regulatory sequences of the CYP11B1 gene were fused to the coding region of the CYP11B2 gene, results in an ectopic expression of aldosterone synthase in the zona fasciculata [4] that is regulated by ACTH. The diagnosis of glucocorticoid-remediable aldo-
Table 1. Monogenetic mineralocorticoid hypertension syndromes

Familial hyperaldosteronism types I and II

Hypertensive forms of congenital adrenal hyperplasia

$11 \beta$-Hydroxysteroid dehydrogenase deficiency

Liddle's syndrome

Activating mutation of mineralocorticoid receptor

Glucocorticoid resistance

steronism had been traditionally made using the dexamethasone suppression test; however, recent studies have shown that several patients with primary aldosteronism and a positive dexamethasone suppression test do not have the chimeric CYP11B1/CYP11B2 gene [5]. Plasma 18-hydroxycortisol determination by an ELISA method is reliable for detecting glucocorticoid-remediable aldosteronism, and it does so better than the dexamethasone suppression test [6]. Genetic testing by either Southern blot [7] or long polymerase chain reaction [8] techniques is sensitive and specific for GRA, and it should be performed in children or young adults with severe or resistant hypertension and a positive family history of earlyonset hypertension and/or premature hemorrhagic stroke [9].

GRA should be treated medically with a glucocorticoid to partially suppress pituitary ACTH secretion. In 
Fig. 2. Monogenetic forms of mineralocorticoid hypertension syndromes. Some monogenetic forms of mineralocorticoid hypertension syndromes are presented. Conditions associated with excessive aldosterone production: (1) familial hyperaldosteronism type I. Conditions not associated with excessive aldosterone production: (2) 11ß-hydroxylase deficiency; (3) $17 \alpha$-hydroxylase deficiency; (4) $11 \beta$-hydroxysteroid dehydrogenase deficiency; (5) glucocorticoid resistance; (6) Liddle's syndrome, and (7) activating mutation of mineralocorticoid receptor.

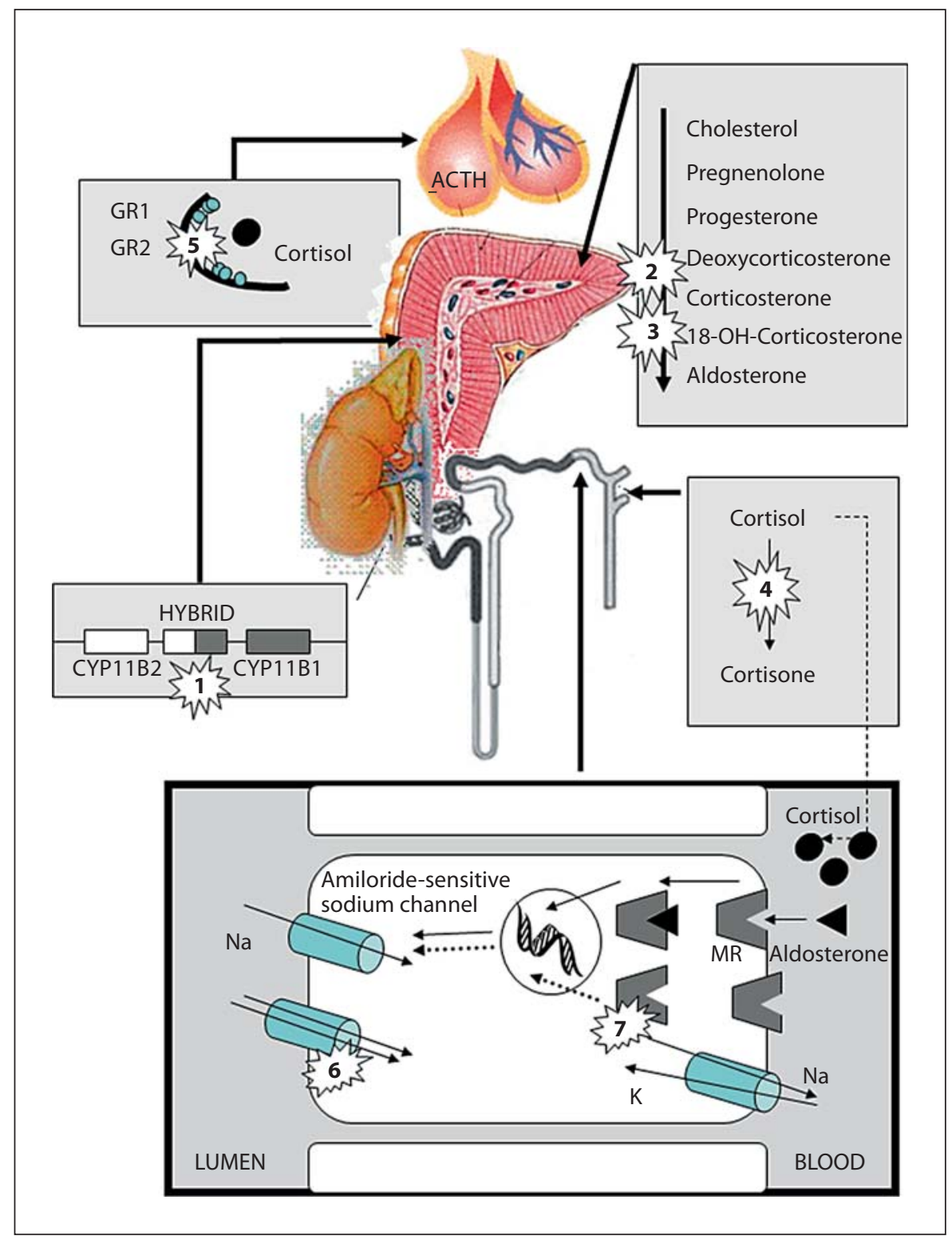

general, the lowest possible dose of glucocorticoid that normalizes blood pressure and/or serum potassium concentration should be used [10]. Treatment with a glucocorticoid may not always normalize blood pressure, and addition of an MR antagonist should be considered in these cases [9].

\section{Familial Hyperaldosteronism Type II}

(OMIM; \#605635)

Familial hyperaldosteronism type II (FH-II) is a hereditary form of primary aldosteronism not attributable to the hybrid CYP11B1/CYP11B2 mutation that causes
GRA; it is characterized by hypersecretion of aldosterone due to adrenocortical hyperplasia, an aldosterone-producing adenoma (APA), or both. In contrast to familial hyperaldosteronism type I (OMIM; \#103900), FH-II is not suppressible by dexamethasone. Although the exact mutation causing this syndrome has not been identified, different studies have associated a locus in chromosome 7p22 [11-13]. Normalization of aldosterone levels or aldosterone receptor blockade is necessary to prevent the morbidity and mortality associated with hypertension, hypokalemia, and cardiovascular damage. For more than four decades, the MR antagonist spironolactone has been 
the agent of choice in the medical treatment of primary hyperaldosteronism. Esplerenone, a new MR antagonist agent, has been suggested. Although less efficacious than spironolactone amiloride, $\mathrm{ENaC}$ antagonists may be useful [9].

Although radiology plays no role in the initial diagnosis, CT and MR imaging have increasingly been used to diagnose APA. However, there is a wide variation in the reported diagnostic performance of CT (sensitivity 40 $100 \%$ ) and MR imaging (sensitivity $70-100 \%$ ) in detecting APA [14].

\section{Conditions Associated with Low or Undetectable Aldosterone}

\section{Hypertensive Forms of Congenital Adrenal}

Hyperplasia (OMIM; \#202010 and 202110)

The most common hypertensive congenital adrenal hyperplasia (CAH) is due to a deficiency in $11 \beta$-hydroxylase (\#202010). It is present in 5-8\% of all CAH cases, occurring in approximately $1-200,000$ live births [15]. This type of $\mathrm{CAH}$ is an autosomal recessive disorder of corticosteroid biosynthesis resulting in androgen excess, virilization, and hypertension. It is caused by a mutation in the CYP11B1 gene, which encodes the $11 \beta$-hydroxylase enzyme, which disrupts the conversion of 11-deoxycortisol to cortisol $[15,16]$. Because of deficient cortisol production, the pituitary secretes large amounts of ACTH, stimulating adrenal steroidogenesis and increasing the plasma levels of 11-deoxycortisol, deoxycorticosterone and androgen precursors. Because deoxycorticosterone is an effective mineralocorticoid, excess causes retention of salt and water and suppression of the PRA and aldosterone, leading to hypertension. The disorder responds to suppressive doses of dexamethasone. Other hypertensive $\mathrm{CAH}$ is caused by a deficiency in $17 \alpha$-hydroxylase (\#202110). This rare form of CAH is caused by defects in cytochrome P450c17, the single enzyme that has $17 \alpha$-hydroxylase and 17,20-lyase activities. This disorder is characterized by moderate arterial hypertension, suppression of the renin-angiotensin system, absent sex steroid synthesis, resulting in female external genitalia in $46, \mathrm{XY}$ patients, and by impaired production of cortisol with a compensatory hypersecretion of ACTH. ACTH stimulates the synthesis of large amounts of deoxycorticosterone and corticosterone, leading to sodium reabsorption and suppression of PRA and SA [17]. The molecular genetic basis has been clarified in at least two dozen patients, identifying at least 17 different lesions in the
P450c17 gene [18-20]. Patients affected may also be treated with suppressive doses of dexamethasone or physiologic doses of hydrocortisone during childhood.

\section{$11 \beta$-Hydroxysteroid Dehydrogenase Deficiency (OMIM; \#218030)}

This syndrome is the result of impaired activity of the enzyme $11 \beta$-hydroxysteroid dehydrogenase type 2 (11ßHSD2). This enzyme is expressed in mineralocorticoid target tissues and is crucial in the kidney, where it normally inactivates cortisol by converting it to cortisone [17, 21]. Thus, when there is congenital absence of $11 \beta-H S D 2$ [22-24], the protective mechanism fails, and cortisol gains inappropriate access to the mineralocorticoid receptor (MR), whose affinity to cortisol is equal to that of aldosterone $[25,26]$. Because the cortisol secretion is nearly 1,000 times higher than that of aldosterone in affected patients, cortisol saturates the MR. The excess cortisol binding produces a hypermineralocorticoid state, which results in hypokalemia, sodium retention and volume expansion, thus suppressing plasma renin and aldosterone secretion. This syndrome is characterized by a high plasma cortisol/cortisone ratio or a high urine tetrahydrocortisol/tetrahydrocortisone ratio that is almost 10 times higher than normal [27]. Although the plasma cortisol half-life is increased, elevated serum cortisol concentrations are not typically present and do not aid in the diagnosis. In patients with congenital absence of $11 \beta-$ HSD2, homozygous inactivating mutations have been identified in more than 20 cases [27-29]. The disorder is inherited as an autosomal recessive trait, and most heterozygous individuals have a normal phenotype. Recently, we looked for the possible contribution of a decreased $11 \beta-H S D 2$ activity in the pathogenesis of low-renin hypertension, and we found that low-renin essential hypertensives had increased serum cortisol/cortisone ratios as compared with normotensive subjects. This suggests that some essential hypertensives with suppressed renin activity may have an impairment in the cortisol inactivation catalyzed by the enzyme 11ß-HSD2 [30]. This type of hypertension responds to spironolactone administration or a low sodium diet, suggesting that it is mediated by the mineralocorticoid (type I) receptor. Administration of cortisol or of ACTH exacerbates the hypertension.

\section{Glucocorticoid Resistance (OMIM; \#138040)}

Glucocorticoid resistance is a rare condition characterized by generalized, partial, target-tissue insensitivity to glucocorticoids. Compensatory elevations in circulat- 
ing adrenocorticotropic hormone (ACTH) concentrations lead to increased secretion of cortisol and adrenal steroids with mineralocorticoid and/or androgenic activity, but without any clinical evidence of hypercortisolism. The clinical spectrum of the condition is broad, ranging from asymptomatic to severe cases of hyperandrogenism, fatigue and/or mineralocorticoid excess. The molecular basis of glucocorticoid resistance has been ascribed to mutations in the human glucocorticoid receptor gene, which impair glucocorticoid signal transduction, thereby altering tissue sensitivity to glucocorticoids [31]. Genetic studies have documented that mutations and polymorphisms at the GR gene might be associated with different metabolic syndromes, such as glucocorticoid resistance, glucocorticoid sensitivity, obesity, and hypertension [14]. The differential diagnosis should be done with Cushing disease.

\section{Liddle's Syndrome (OMIM; \#177200)}

Liddle's syndrome is caused by mutations in the subunits of the renal sodium epithelial channel [32-34]. The amiloride-sensitive epithelial channel is considered the rate-limiting step for sodium absorption in the distal nephron, and it is composed of three subunits named $\alpha$, $\beta$ and $\gamma[35,36]$. In Liddle's syndrome, mutations have been found in the $\beta$ and $\gamma$ subunits. Because of these mutations, a constitutive activation of the epithelial channel leads to increased sodium absorption and volume expansion. This disorder is inherited as an autosomal dominant disorder in which affected patients present with hypertension, suppressed PRA, and low aldosterone levels. The defect in the sodium channels of the distal nephron results in excessive salt absorption and potassium wasting. $\mathrm{ENaC}$ also has been implicated as a candidate gene for the development of essential hypertension. A potentially polymorphic repetitive region (GT dinucleotide short tandem repeat [STR]) was identified in intron 8 of $\beta$ $\mathrm{ENaC}$ gene (SCNN1B). We have identified a polymorphic GT-STR in the $\beta$-ENaC gene that is present in patients with essential hypertension and normotensive patients in the Chilean population. Biochemical analysis showed a possible linkage between this polymorphic region and hypertension characterized by low renin. An in vitro assay has suggested that GT-STR could regulate $\beta$-ENaC expression [37]. A genetic analysis of the amiloride-sensitive $\mathrm{ENaC}$ is recommended in assessing patients with low-renin, salt-sensitive hypertension whose blood pressure is not responsive to spironolactone treatment [38]. This disorder responds to inhibitors of epithelial sodium transport, e.g., triamterene [39]. Affected patients also re- spond to renal transplantation, which results in normalization of blood pressure and of electrolyte abnormalities.

\section{Activating Mutation of Mineralocorticoid Receptor (OMIM; \#605115)}

This disorder can be caused by mutation in the MR gene in the locus 4q31.1 (OMIM; 600983). A gain of function mutation resulting in the substitution of leucine for serine at codon 810 (S810L) in the human MR (MR) is responsible for early-onset hypertension that is exacerbated in pregnancy. All steroids, including progesterone, that display antagonist properties when bound to the wild-type MR are able to activate the mutant receptor (MR(L810)). These findings suggest that progesterone may contribute to the dramatic aggravation of hypertension in MR(L810) carriers during pregnancy. However, the steroid(s) responsible for hypertension in MR (L810) carriers (men and nonpregnant women) has not yet been identified [40].

\section{Genes Contribute to the Phenotype of Essential Hypertension}

Angiotensin is formed from a precursor, angiotensinogen, which is produced by the liver and found in the $\alpha$ globulin fraction of plasma. Renin cleaves from angiotensinogen a terminal decapeptide, angiotensin I. This is further altered by the enzymatic removal of a dipeptide to form angiotensin II. Angiotensin II is an important effector controlling blood pressure and volume in the cardiovascular system. Angiotensin II interacts with two different subtypes of cell surface receptors, types 1 and 2 (OMIM; AGTR2, 300034). Type 1 receptors seem to mediate the major cardiovascular effects of angiotensin II.

\section{Angiotensinogen (OMIM; \#106150)}

Caulfield et al. [41] investigated linkage between the angiotensinogen (AGT) gene locus to essential hypertension in the 63 multiplex families. This linkage was consistently maintained in the subgroup of subjects with diastolic pressure $>100 \mathrm{~mm} \mathrm{Hg}$ and in the subgroups classified according to gender, providing strong and consistent support for the linkage of regions within or close to the AGT gene to essential hypertension.

Molecular variants in the AGT gene, including M235T, T174M, and a mutation in the promoter region that involves the presence of an adenine (A) instead of a guanine (G) 6 bp upstream from the transcription initiation site 
(G-6A), have also been reported to have a positive correlation with hypertension [42]. Of the molecular variants of AGT that have been identified, a significant association with hypertension was observed with 2 amino acid substitutions, M235T and T174M. Additionally, in an ethnically homogeneous population of Japanese patients, T235 was associated with essential hypertension [43]. Thus, ethnicity may make a significant difference in the role of various genes in certain complex traits [44]. We demonstrated that there is a high prevalence of the T235 variant in our Hispanic population. The slight difference that we found between the prevalence of the T235 variant in hypertensive and normotensive subjects was not statistically significant and did not permit us to establish an association between the T235 variant and essential hypertension [45]. Recently, the interaction among G-6A, M235T and T174M polymorphisms in combinations or haplotypes was significantly associated with a high plasma aldosterone concentration and low PRA, suggesting that these interactions are associated with low-renin hypertension [46].

\section{Angiotensin I-Converting Enzyme (OMIM; \#106180)}

The angiotensin converting enzyme (ACE) or kinase II is a dipeptidyl carboxypeptidase that plays an important role in blood pressure regulation and in electrolyte balance by hydrolyzing angiotensin I into angiotensin II, a potent vasopressor, and aldosterone-stimulating peptide. The enzyme is also able to inactivate bradykinin, a potent vasodilator. The insertion/deletion ACE polymorphism (ACE I/D) regulates different levels of circulating and tissue ACE activities, which may induce diverse adrenergic responses to physiological stimuli. The presence of the D allele on the ACE gene in middle-aged hypertensive patients determines higher circulating ACE activity, but not increased sympathetic activity, in response to submaximal exercise [47].

\section{Angiotensin Receptor-1 (OMIM; \#106165)}

The vasopressor angiotensin II regulates vascular contractility and blood pressure through binding to type 1 angiotensin II receptors. Two subtypes of angiotensin II type 1 receptors, $1 \mathrm{~A}$ (AGTR1A) and 1B (AGTR1B), have been identified in human, rat, and mouse. The AGTR1A and AGTR1B share substantial sequence homology and wide tissue distributions [48]. Variants in the human AGTR1A gene may affect blood pressure in the human [49].

In summary, mineralocorticoid hypertension should be suspected in patients with an early onset of hypertension in the presence of a strong family history of hypertension associated with low PRA, with or without hyperaldosteronism. Clinical manifestations, plasma or urinary steroid tests, and imaging tests can aid in the diagnosis of some patients with this syndrome. However, genetic tests, which are available in some tertiary references centers, allow an accurate and definitive diagnosis.

\section{References}

1 Marteau JB, Zaiou M, Siest G, Visvikis-Siest S: Genetic determinants of blood pressure regulation. J Hypertens 2005;2127-2143.

2 Vehaskari VM: Heritable forms of hypertension. Pediatr Nephrol 2007 [Epub ahead of print].

3 Stowasser M, Gordon RD: Monogenic mineralocorticoid hypertension. Best Pract Res Clin Endocrinol Metab 2006;20:401-420.

$\checkmark 4$ Lifton RP, Dluhy RG, Powers M, Rich GM, Cook S, Ulick S, Lalouel JM: A chimaeric $11 \beta$-hydroxylase/aldosterone synthase gene causes glucocorticoid-remediable aldosteronism and human hypertension. Nature 1992;355:262-265.

5 Fardella CE, Pinto M, Mosso L, GómezSánchez C, Jalil J, Montero J: Genetic study of patients with dexamethasone-suppressible aldosteronism without the chimeric CYP11B1/CYP11B2 gene. J Clin Endocrinol Metab 2001;86:4805-4807.
$>6$

Mosso L, Gómez-Sánchez CE, Foecking MF, Fardella C: Serum 18-hydroxycortisol in primary aldosteronism, hypertension, and normotensives. Hypertension 2001;38:688-691.

$\checkmark 7$ Takeda Y, Miyamori I, Yoneda T, Iki K, Hatakeyama H, Blair IA, Hsieh FY, Takeda R: Synthesis of corticosterone in the vascular wall. Endocrinology 1994;135:2283-2286.

8 Jonsson J, Klemm S, Tunny T, Stowasser M, Gordon R: A new genetic test for familial hyperaldosteronism type I aids in the detection of curable hypertension. Biochem Biophys Res Commun 1995;207:565-571.

$\checkmark 9$ Funder JW, Carey RM, Fardella C, GomezSanchez CE, Mantero F, Stowasser M, Young WF Jr, Montori VM; Endocrine Society: Case detection, diagnosis, and treatment of patients with primary aldosteronism: an endocrine society clinical practice guideline. J Clin Endocrinol Metab 2008;93:3266-3281.
10 Stowasser M, Bachmann AW, Huggard PR, Rossetti TR, Gordon RD: Treatment of familial hyperaldosteronism type I: only partial suppression of adrenocorticotropin required to correct hypertension. J Clin Endocrinol Metab 2000;85:3313-3318.

11 Lafferty AR, Torpy DJ, Stowasser M, Taymans SE, Lin JP, Huggard P, Gordon RD, Stratakis CA: A novel genetic locus for low renin hypertension: familial hyperaldosteronism type II maps to chromosome 7 (7p22). J Med Genet 2000;37:831-835.

12 Sukor N, Mulatero P, Gordon RD, So A, Duffy D, Bertello C, Kelemen L, Jeske Y, Veglio F, Stowasser M: Further evidence for linkage of familial hyperaldosteronism type II at chromosome 7p22 in Italian as well as Australian and South American families. J Hypertens 2008;26:1577-1582. 
$\checkmark 13$ So A, Duffy DL, Gordon RD, Jeske YW, LinSu K, New MI, Stowasser M: Familial hyperaldosteronism type II is linked to the chromosome 7 p22 region but also shows predicted heterogeneity. J Hypertens 2005;23: 1477-1484.

-14 Patel SM, Lingam RK, Beaconsfield TI, Tran TL, Brown B: Role of radiology in the management of primary aldosteronism. Radiographics 2007;27:1145-1157.

15 White P, Curnow K, Pascoe L: Disorders of steroid 11 $\beta$-hydroxylase isozymes. Endocr Rev 1994;15:421-438.

-16 White PC, Dupont J, New MI, Leiberman E, Hochberg Z, Rösler A: A mutation in CYP11B1 (Arg-448 $\rightarrow$ His) associated with steroid 11ß-hydroxylase deficiency in Jews of Moroccan origin. J Clin Invest 1991;87: 1664-1667.

-17 Fardella CE, Miller WL: Molecular biology of mineralocorticoid metabolism. Annu Rev Nutr 1996;16:443-470.

-18 Yanase T, Simpson ER, Waterman MR: $17 \alpha-$ Hydroxylase/17,20-lyase deficiency: from clinical investigation to molecular definition. Endocr Rev 1991;12:91-108.

-19 Fardella CE, Zhang LH, Mahachoklertwattana $\mathrm{P}$, Lin D, Miller WL: Deletion of amino acids Asp487-Ser488-Phe489 in human cytochrome $\mathrm{P} 450 \mathrm{c} 17$ causes severe $17 \alpha$-hydroxylase deficiency. J Clin Endocrinol Metab 1993;77:489-493.

-20 Fardella CE, Hum DW, Homoki J, Miller WL: Point mutation of Arg440 to His in cytochrome P450c17 causes severe $17 \alpha$-hydroxylase deficiency. J Clin Endocrinol Metab 1994;79:160-164.

$\checkmark 21$ White PC: Inherited forms of mineralocorticoid hypertension. Hypertension 1996;28: 927-936.

-22 Stewart PM, Corrie JE, Shackleton CH, Edwards CR: Syndrome of apparent mineralocorticoid excess. A defect in the cortisol-cortisone shuttle. J Clin Invest 1988;82: 340-349.

-23 Wilson RC, Krozowski ZS, Li K, Obeyesekere VR, Razzaghy-Azar M, Harbison MD, Wei JQ, Shackleton CH, Funder JW, New MI: A mutation in the HSD11B2 gene in a family with apparent mineralocorticoid excess. J Clin Endocrinol Metab Jul 1995;80:22632266.

-24 Mune T, Rogerson FM, Nikkilä H, Agarwal AK, White PC: Human hypertension caused by mutations in the kidney isozyme of $11 \beta$ hydroxysteroid dehydrogenase. Nat Genet 1995; 10:394-399.

-25 Arriza JL, Weinberger C, Cerelli G, Glaser TM, Handelin BL, Housman DE, Evans RM: Cloning of human mineralocorticoid receptor complementary DNA: structural and functional kinship with the glucocorticoid receptor. Science 1987;237:268-275.

26 Rupprecht R, Reul JM, van Steensel B, Spengler D, Söder M, Berning B, Holsboer F, Damm K: Pharmacological and functional characterization of human mineralocorticoid and glucocorticoid receptor ligands. Eur J Pharmacol 1993;247:145-154.
27 Wilson RC, Dave-Sharma S, Wei JQ, Obeyesekere VR, Li K, Ferrari P, Krozowski ZS Shackleton $\mathrm{CH}$, Bradlow L, Wiens T, New MI: A genetic defect resulting in mild lowrenin hypertension. Proc Natl Acad Sci USA 1998;95:10200-10205

28 Stewart PM: Mineralocorticoid hypertension. Lancet 1999;353:1341-1347.

29 Stewart PM, Krozowski ZS, Gupta A, Mil ford DV, Howie AJ, Sheppard MC, Whorwood CB: Hypertension in the syndrome of apparent mineralocorticoid excess due to mutation of the $11 \beta$-hydroxysteroid dehydrogenase type 2 gene. Lancet 1996;347:8891.

30 Carvajal CA, Romero DG, Mosso LM, González AA, Campino C, Montero J, Fardella CE: Biochemical and genetic characterization of $11 \beta$-hydroxysteroid dehydrogenase type 2 in low-renin essential hypertensives. J Hypertens 2005;23:71-77.

31 Charmandari E, Kino T: Novel causes of generalized glucocorticoid resistance. Horm Metab Res 2007;39:445-450.

- 32 Shimkets RA, Warnock DG, Bositis CM Nelson-Williams C, Hansson JH, Schambelan M, Gill JR Jr, Ulick S, Milora RV, Findling JW, et al: Liddle's syndrome: heritable human hypertension caused by mutations in the $\beta$ subunit of the epithelial sodium channel. Cell 1994;79:407-414.

33 Hansson JH, Schild L, Lu Y, Wilson TA, Gautschi I, Shimkets R, Nelson-Williams C, Rossier BC, Lifton RP: A de novo missense mutation of the $\beta$ subunit of the epithelial sodium channel causes hypertension and Liddle syndrome, identifying a proline-rich segment critical for regulation of channel activity. Proc Natl Acad Sci USA 1995;92: 11495-11499.

34 Tamura H, Schild L, Enomoto N, Matsui N, Marumo F, Rossier BC: Liddle disease caused by a missense mutation of $\beta$ subunit of the epithelial sodium channel gene. J Clin Invest 1996;97:1780-1784.

35 Canessa CM, Schild L, Buell G, Thorens B, Gautschi I, Horisberger JD, Rossier BC: Amiloride-sensitive epithelial $\mathrm{Na}^{+}$channel is made of three homologous subunits. Nature 1994;367:463-467.

36 Renard S, Lingueglia E, Voilley N, Lazdunski M, Barbry P: Biochemical analysis of the membrane topology of the amiloride-sensitive $\mathrm{Na}^{+}$channel. J Biol Chem 1994;269: 12981-12986.

37 González AA, Carvajal CA, Riquelme E, Krall PM, Munoz CR, Mosso LM, Kalergis AM, Fardella CE: A polymorphic GT short tandem repeat affecting $\beta$-ENaC mRNA expression is associated with low renin essential hypertension. Am J Hypertens 2007;20: 800-806.
38 Uehara Y, Sasaguri M, Kinoshita A, Tsuji E, Kiyose H, Taniguchi H, Noda K, Ideishi M, Inoue J, Tomita K, Arakawa K: Genetic analysis of the epithelial sodium channel in Liddle's syndrome. J Hypertens 1998;16:11311135 .

39 Botero-Velez M, Curtis JJ, Warnock DG: Brief report: Liddle's syndrome revisited - a disorder of sodium reabsorption in the distal tubule. N Engl J Med 1994;330:178-181.

40 Rafestin-Oblin ME, Souque A, Bocchi B, Pinon G, Fagart J, Vandewalle A: The severe form of hypertension caused by the activating S810L mutation in the mineralocorticoid receptor is cortisone related. Endocrinology 2003;144:528-533.

41 Caulfield M, Lavender P, Farrall M, Munroe P, Lawson M, Turner P, Clark AJL: Linkage of the angiotensinogen gene to essential hypertension. N Engl J Med 1994;330:16291633.

42 Li NF, Zhou L, Wu WD, Shi Y, Wang XL, Wang J, Li HJ, Zhang DL, Zu H, Ouyang WJ, Bu KL, Zhou KM, Cheng QY, Guli N, Zhu $\mathrm{DH}$ : The relationship between the variants in $5^{\prime}$ upstream core promoter $A(-6) G$ and $\mathrm{A}(-20) \mathrm{C}$ of angiotensinogen gene and essential hypertension in Kazakans of Xinjiang (in Chinese). Zhonghua Yi Xue Yi Chuan Xue Za Zhi 2004;21:23-28.

43 Hata A, Namikawa C, Sasaki M, Sato K, Nakamura T, Tamura K, Lalouel JM: Angiotensinogen as a risk factor for essential hypertension in Japan. J Clin Invest 1994;93: 1285-1287.

44 Niu T, Xu X, Rogus J, Zhou Y, Chen C, Yang J, Fang Z, Schmitz C, Zhao J, Rao VS, Lindpaintner K: Angiotensinogen gene and hypertension in Chinese. J Clin Invest 1998; 101:188-194.

45 Fardella CE, Claverie X, Vignolo P, Montero J, Villarroel L: T235 variant of the angiotensinogen gene and blood pressure in the Chilean population. J Hypertens 1998;16:829833.

46 Nejatizadeh A, Kumar R, Stobdan T, Goyal AK, Gupta M, Javed S, Pasha MQ: Significance of angiotensinogen gene haplotypes and genotypes combinations in hypertension. J Hypertens 2008;26:1094-1101.

47 Jalil JE, Córdova S, Ocaranza M, Schumacher E, Braun S, Chamorro G, Fardella C, Lavandero S: Angiotensin I-converting enzyme insertion/deletion polymorphism and adrenergic response to exercise in hypertensive patients. Med Sci Monit 2002;8:CR566CR571.

48 Ito M, Oliverio MI, Mannon PJ, Best CF, Maeda N, Smithies O, Coffman TM: Regulation of blood pressure by type 1A angiotensin II receptor gene. Proc Natl Acad Sci USA 1995;92:3521-3525.

-49 Bonnardeaux A, Davies E, Jeunemaitre X, Fery I, Charru A, Clauser E, Tiret L, Cambien F, Corvol P, Soubrier F: Angiotensin II type 1 receptor gene polymorphisms in human essential hypertension. Hypertension 1994;24:63-69. 